\title{
Perception of Quality of Life among Anesthesiologists and Non-Anesthesiologists
}

\author{
Helena Maria Arenson-Pandikow, TSA ${ }^{1}$, Leandro Turra Oliviera ${ }^{2}$, Carmen Regina Bortolozzo ${ }^{3}$, \\ Simone Petry ${ }^{4}$, Thiago Fonseca Schuch ${ }^{4}$
}

Summary: Arenson-Pandikow HM, Oliviera LT, Bortolozzo CR, Petry S, Schuch TF- Perception of Quality of Life Among Anesthesiologists and Non-Anesthesiologists.

Background and objectives: Literature points out routine factors with negative impact on anesthesiologists' quality of life. This study aims to compare the perception of quality of life of anesthesiologists and non-anesthesiologists.

Method: Transversal study based on three specific questionnaires (epidemiological, WHOQOL-BREF and SF-12®) applied in anesthesiologists (Group A) and non-anesthesiologists (Group NA), of a general university hospital and a third group of anesthesiologists from inner state (Group I). The analysis of epidemiological variables and the ones related to quality of life domains of WHOQOL were interpreted by multivariate analysis (SPSS program).

Results: The number of WHOQOL-BREF respondents were: Group A = 67; Group NA = 69; Group I = 53. The anesthesiologists from Group I were excluded from the study due to an inadequate sample for statistical analysis. The total number of respondents to check the SF-12 ${ }^{\circledR}$ score was 61 in Group A and 68 in Group NA. For the WHOQOL-BREF tool, the physical domain scores were $72.97 \pm 11.78$ for Group A and $77.17 \pm 10.85$ for Group NA ( $p<0.05$ ); the psychological domain scores were $66.44 \pm 13.66$ for Group A and $71.79 \pm 11.48$ for Group NA ( $<<0.05)$; the social relationship domain scores were $64.67 \pm 19.08$ for Group A and $73.36 \pm 15.37$ for Group NA $(p<0.01)$; and the environment domain scores were $68.14 \pm 11.56$ for Group A and $72.37 \pm 10.07$ for Group NA $(p<0.05)$. In SF-12 ${ }^{\circledR}$, both physical and mental components did not show statistical differences.

Conclusions: The perception of the anesthesiologists' quality of life was consistently inferior to other physicians in general, for the studied sample.

Keywords: Quality of Life; Anesthesia; Professional Practice; Evaluation Studies; Questionnaires; World Health Organization.

()2012 Elsevier Editora Ltda. All rights reserved.

\section{INTRODUCTION}

A physician spends practically all the time in alert state while practicing his profession. Taking care of patients, attending meetings, unexpected work situations, the need of constant update and continued education generate a gradual and increasing overload. An oppressive sensation remains that, in fact, he/she resigned to live with less than the minimum, and created an increasing abyss between the most imperious preoccupations of both routine and familiar fields and any anxiety

Received from Hospital das Clínicas de Porto Alegre, Brazil.

1. PhD, University of London - England; Co-Responsible for CET/SBA; Service of Anesthesia and Perioperative Medicine (SAMPE from Portuguese) of Hospital de Clínicas of Porto Alegre (HCPA); Associate Professor in Anesthesiology, Department of Surgery, Faculty of Medicine (FAMED) , Universidade Federal do Rio Grande do Sul (UFRGS)

2. Anesthesiologist, Pediatric Intensivist; SAMPE of the HCPA

3. Anesthesiologist, Specialist in Pain and Palliative Medicine; SAMPE of the HCPA

4. Anesthesiologist; SAMPE of the HCPA

Submitted on May 3, 2011.

Approved on August 3, 2011.

Correspondence to:

Dra. Helena Maria Arenson-Pandikow

Rua André Puente, 185 Ap. 701

Bairro Independência

90035150 - Porto Alegre, RS, Brazil

E-mail: hpandikow@hcpa.ufrgs.br about the future ${ }^{1}$. In this panorama the physician experiences loss of sleep, alteration of psycho-structure, self-esteem and professional performance, with lots of mixed feelings. On the one hand, is the pleasure to perform the profession of choice. On the other hand, the physician finds him/herself within a health system that became an engine to enable mass treatments, making him/her feel disposable; a mere spare part. The cherished autonomy became encapsulated. The physician lost his/her freedom. In this context, the anesthesiologist, due to peculiarities of his specialty, is familiar with additional stress situations, resulting from sleep privation by night calls, highly mutant work environment that incorporates noise pollution (surgical and aspiration equipment, electrocautery, monitors, alarms, ventilators, among others), radiation exposure, excessive heat or cold, uncomfortable chairs and poorlydesigned operating rooms ${ }^{2,3}$. Other relevant factors are the lack of control over workload, the difficulty in communicating with staff, and the permanent subordination to the surgeons' schedule ${ }^{4}$.

In the literature, considerable contributions support the prevalence of psycho-physiological alterations connected to professional performance ${ }^{5-8}$. Such evidences require reflection and demand structural changes in the anesthetic environment. One should start by the identification of intangible 
factors, detrimental to quality of life at workplace, which are not recognized and, therefore, not duly solved.

The present study aimed to evaluate the anesthesiologists' quality of life and of a control group of non-anesthesiologist representative of the medical population of Rio Grande do Sul, for the comparative verification of the real situation of anesthesiologists in our environment.

\section{MATERIAL AND METHODS}

\section{Study design}

This was a transversal study to analyze the data collected from three specific forms that were anonymously applied to participants of the project from August 2007 to March 2008. The three questionnaires were: epidemiological questionnaire related to the work routine; the World Health Organization Quality of Life Group - WHOQOL-BREF and the simplified version of SF-36® (Medical Outcomes Study 36 - Item ShortForm Health Survey); SF-12®.

\section{Definition of groups and sample size}

Group A consisted of anesthesiologists working at the Service of Anesthesia and Perioperative Medicine (SAMPE) of Hospital de Clínicas de Porto Alegre (HCPA). The Group NA consisted of physicians from different specialties, non-anesthesiologists, also working at HCPA. The sample was selected proportion- ally to the specialties registered at the Regional Council of Medicine of Rio Grande do Sul. Group I consisted of anesthesiologists from three cities of the inner state of Rio Grande do Sul. Physicians who did not want to participate in the project or did not sign the consent form were excluded as well as those who did not fill the forms entirely and physicians who practiced their professional activities both in the capital and inner state. Considering the limit of number of physicians hired by SAMPE (70), in order to obtain $\alpha=0.05$ and $\beta=80 \%$, a sample size of 64 individuals in each group was necessary.

\section{Statistical analysis}

Data obtained were stored in a specific database, using Excel Microsoft ${ }^{\circledR}$ spreadsheet and analyzed in SPSS (Statistical Package for Social Sciences) program to study epidemiological variables. The quality of life scores were processed by specific models of each tool used and correlations with epidemiological variables were obtained by multivariate analysis. In all analysis, two standard deviations were considered, $<0.05$, as statistically significant.

\section{RESULTS}

The results of the epidemiological questionnaire applied in the three groups are described in Table I.

Groups A and I did not differ statistically from Group NA on age, nights on duty or on call during the week or weekends and the practice of physical or leisure activities.

Table I - Results of Epidemiological Questionnaire Applied in Three Groups

\begin{tabular}{|c|c|c|c|}
\hline & $\begin{array}{l}\text { Group NA } \\
\text { Non- anesthesiologists } \\
(n=69)\end{array}$ & $\begin{array}{l}\text { Group A } \\
\text { Anesthesiologists from the } \\
\text { capital }(n=67)\end{array}$ & $\begin{array}{l}\text { Group I } \\
\text { Anesthesiologists from the } \\
\text { inner state }(n=53)\end{array}$ \\
\hline Male gender & $56.4 \%$ & $48.5 \%$ & $\begin{array}{l}83 \% \\
p<0.01\end{array}$ \\
\hline Graduation time & $\begin{array}{l}15.81 \\
p<0.05\end{array}$ & 12.54 & $\begin{array}{l}15.55 \\
p<0.05\end{array}$ \\
\hline Hours worked daily & $9.91 \pm 2.79$ & $9.32 \pm 2.58$ & $\begin{array}{l}11.20 \pm 1.59 \\
p<0.01\end{array}$ \\
\hline Time of weekly rest & $1.83 \pm 2.05$ & $2.12 \pm 1.34$ & $\begin{array}{l}0.97 \pm 0.80 \\
p<0.01\end{array}$ \\
\hline Night shift in the previous 2 weeks & $2.19 \pm 3.12$ & $1.68 \pm 1.74$ & $\begin{array}{l}2.83 \pm 1.72 \\
p<0.01\end{array}$ \\
\hline Hierarchy relationship at work & $\begin{array}{l}47.2 \% \\
p<0.01\end{array}$ & $89.7 \%$ & $98.6 \%$ \\
\hline Article read in 2 previous weeks & $\begin{array}{l}89.1 \% \\
p<0.01\end{array}$ & $76.5 \%$ & $67.9 \%$ \\
\hline Periods of 7 or more days off/year & $\begin{array}{l}2 \text { periods } \\
77.6 \%\end{array}$ & $\begin{array}{l}2 \text { periods } \\
64.1 \%\end{array}$ & $\begin{array}{l}3 \text { or more periods } \\
88.5 \% \\
p<0.01\end{array}$ \\
\hline
\end{tabular}


The total number of participants in each group to the WHOQOL-BREF score was 67 in Group A, 69 in Group NA and 51 in Group I. For the SF-12 score the number of participants was 61, 68 and 52 for the Groups A, NA and I, respectively. Since Group I did not reach the necessary $n$ to apply the quality of life scores, this group could not be included in the analysis.

Table II - Total Number of Participants in Each Group for WHOQOL-BREF Score

\begin{tabular}{lll}
\hline Domains & $\begin{array}{l}\text { Capital anesthesiologists } \\
(\mathrm{A})\end{array}$ & $\begin{array}{l}\text { Non-anesthesiologists } \\
(\mathrm{NA})\end{array}$ \\
\hline Physical & $72.97 \pm 11.78(\mathrm{p}<0.05)$ & $77.17 \pm 10.85$ \\
Psychological & $66.44 \pm 13.66(\mathrm{p}<0.05)$ & $71.79 \pm 11.48$ \\
SR & $64.67 \pm 19.08(\mathrm{p}<0.01)$ & $73.36 \pm 15.37$ \\
Environment & $68.14 \pm 11.56(\mathrm{p}<0.05)$ & $72.37 \pm 10.07$ \\
Overall & $62.31 \pm 19.15(\mathrm{p}<0.01)$ & $72.82 \pm 14.05$ \\
\hline
\end{tabular}

SR: social relationships.

Table III - Total Number of Participants in Each Group for SF-12 Score

\begin{tabular}{lll}
\hline & $\begin{array}{l}\text { Capital anesthesiologists } \\
\text { Group A }\end{array}$ & $\begin{array}{l}\text { Non-anesthesiologists } \\
\text { Group NA }\end{array}$ \\
\hline PCS $^{*}$ & $55.24 \pm 4.91$ & $55.78 \pm 4.28$ \\
MCS $^{*}$ & $48.03 \pm 10.80$ & $51.07 \pm 8.77$ \\
\hline
\end{tabular}

*PCS: physical component summary; ${ }^{*} \mathrm{MCS}$ : mental component summary.

Table IV - Multivariate Analysis:

Capital Anesthesiologists vs Non-Anesthesiologists

\begin{tabular}{llll}
\hline Domains & $\begin{array}{l}\text { Worst } \\
\text { relationship } \\
\text { with staff }\end{array}$ & $\begin{array}{l}\text { Smallest time } \\
\text { devoted to } \\
\text { update }\end{array}$ & $\begin{array}{l}\text { Smallest work } \\
\text { experience }\end{array}$ \\
\hline $\begin{array}{l}\text { Physical } \\
\text { Psychological }\end{array}$ & $\mathrm{x}$ & $\mathrm{x}$ & \\
$\begin{array}{l}\text { Social relationships } \\
\text { Environment }\end{array}$ & $\mathrm{x}$ & $\mathrm{x}$ & $\mathrm{x}$ \\
Overall & $\mathrm{x}$ & & \\
\hline
\end{tabular}

Group A had significantly lower scores compared with Group NA in the WHOQOL-BREF tool (Table II) on the following domains: physical, psychological, social relationship, environment and general quality of life. But SF-12® tool scores (Table III) did not significantly differ among groups.

When the multivariate regression was performed (Table IV) to correlate epidemiological variables with altered scores of anesthesiologists' Group A, the reduced participation in scientific events was the predictor of lower scores in the environment domain. The worst relationship with staff was the predictor of lower scores on following domains: psychological, social relationships and general quality. The less time of graduation was the predictor of lower scores in the environment domain.

\section{DISCUSSION}

Literature is full of studies that report different types of stress that anesthesiologists undergo ${ }^{2-8}$, but there is no specific study that indicates their perception of quality of life when compared with doctors in general. On the other hand, the level of anesthesiologists' satisfaction with the profession is high 4,9 , a fact that could soothe the hard conjuncture variables and contribute to a better perception of their quality of life. However, our data do not support this assumption. When we compared capital anesthetists with physicians in general, it was evident that their "quality of life" was inferior in many aspects of the analysis. When the same comparison was proposed with "inner state anesthetists", the size of group sample was not enough.

Factors that could interfere with the level of anesthesiologists' quality of life have already been shown in previous publications ${ }^{2-8}$. Recently, Mansour ${ }^{10}$ compared a group of anesthesiologists with diabetic patients and other employees of the same hospital and demonstrated significantly higher general fatigue scores in anesthesiologists. Chia ${ }^{11}$ pointed out to an inverse relationship between emotional exhaustion and professional satisfaction by analyzing data of anesthesia residents. Nyssen et al. ${ }^{4}$ documented that even though the stress levels measured in were not higher than workers in general, $40 \%$ of them suffered from burnout syndrome with higher rates among young residents. In the American residency programs in anesthesia, an improvement in the residents well being was detected three years after the implementation of limit of duty hours ${ }^{12}$. Other data reinforce an increasing tendency among American and Australian anesthesiologists in reducing the weekly workload directly related to anesthesia

In the present study, which applied the duly-validated WHOQOL-BREF tool ${ }^{14,15}$, including for groups in the work environment ${ }^{16}$, Group A had significantly inferior quality of life scores in the total analyzed domains (psychological, social relationship, environment and physical). However, when applying the SF-12® instrument no differences among groups were detected. This could be attributed to the instrument used, which is more indicated to check clinical outcomes and differentiate health states when compared with WHOQOL-BREF 17. In fact, the present approach did not analyze populations with specific comorbidity neither groups with some type of limiting disease. But, regarding the choice of the simplified version of the tool (12 questions), which would abbreviate the time to fill in the three questionnaires, the sample size in HCPA was reduced to the appropriate achievement of outcomes.

With regard to Group I whose evaluation was impracticable for not having a statistically sufficient sample, we will try to extend this survey to other places in the state.

Based on the work profile from Table I, the multivariate analysis detected a positive relationship between the inferior scores of the anesthesiologists from Group A and their worse relationship with the staff. This finding strengthens the opinion by Jenkins et al. ${ }^{9}$ about the significant impact of the surgeon's attitude towards the anesthesiologist and his professional satisfaction. The real importance of this component became 
even more evident when we demonstrated this relationship in our study in more than one domain (psychological and social relationships) and overall. Other inferior scores related to the factor "less time devoted to update/education" in social relationships domain, indicate the importance of trips to congresses, attendance to seminars out of the work environment and discussion of articles, among others. Those are fundamental to renovate/acquire cognitive, affective and social skills. The group of Kinz et al. ${ }^{18}$ defined well the relevance of social and personal relationships (more reading time, making friends, family relationships) when they showed the anesthesiologist trusts more his personal and intellectual skills to handle daily demands, overcoming even the support of colleagues or bosses. In the present study, reduced profession time showed correlation with inferior scores in the environment domain, where situations like security, quality of work environment and mobility are evaluated. A study by Morais et al. ${ }^{19}$ favors these findings by confirming the high stress levels among anesthesiologists, being the longer time of professional experience correlated with smaller rates of emotional fatigue. The frequent changes in workplace would cause less stress, privilege commonly acquired only after some years.
In our search for elements connected to the quality of life in the anesthesiologist's work when compared with other physicians, in addition to the limitations attributed to the sample size, it would be appropriate to mention a peculiar characteristic when it comes to professionals linked to a school hospital, who receive more pressure from the academic environment. This condition, equally valid for the control group, may not adequately represent physicians working in non-educational institutions. However, it became clear that, in the specific case of anesthesiologists, their perception of quality of life is much lower if compared with other physicians.

\section{CONCLUSIONS}

The perception of the anesthesiologist's quality of life was consistently inferior to other physicians for the specific sample. The outcome of this study contributes with meaningful information to guide curative actions, either individual, in groups or by the class' representative bodies about organizational, environmental and work logistics that are possibly damaging the occupational well being of the class. More research is required to assess possible differences in quality of life of anesthesiologists working in regions outside the capital. 


\section{REFERENCIAS / REFERENCES}

1. Editorial da Revista do CREMERS nº43, junho de 2007.

2. Weinger MD, Englund CE - Ergonomic and human factors affecting anesthesic vigilance and monitoring performance in the operating room environment. Anesthesiology, 1990;73:995-1021.

3. Berry AJ, Katz JD - Hazards of working in the operating room. In Barash PG, Cullen BF, Stoelting RK, eds. Clinical anesthesia. $2^{\text {nd }}$ ed. Philadelphia, JB Lippincott, 1992;89-114.

4. Nyssen AS, Hansez I, Baele P et al. - Occupational stress and burnout in anaesthesia. Br J Anaesth, 2003;90:333-337.

5. Jackson SH - The role of stress in anaesthesists' health and well-being. Acta Anaesthesiol Scand, 1999;43:538-602.

6. Xiao Y, Mackenzie CF, Bernhard W et al. - Dynamics of stress during elective and emergency airway management. Anesthesiology, 1996;85(3A):A957.

7. Toung TJ, Donham RT, Rogers MC - Effect of previous medical training on the stress of giving anesthesia. Anesthesiology, 1986;65(3A):A473.

8. Azar I, Sophie S, Lear E - The cardiovascular response of anesthesiologists during induction of anesthesia. Anesthesiology, 1985;63(3A):A76.

9. Jenkins K, Wong D - A survey of professional satisfaction among Canadian anesthesiologists. Can J Anesth, 2001;48(7):637-645.

10. Mansour A - The occupational fatigue in anesthesiologists: illusion or real? Middle East J Anesthesiol, 2010;20(4):529-534.

11. Chia $\mathrm{AC}$ - Comparison of stress in anaesthetic trainees between Hong Kong and Victoria, Australia. Anaesth Intensive Care, 2008;36(6);855-862.

12. Swide CE - Duty hours restriction and their effect on resident education and academic departments: the american perspective. Curr Opin Anaesthesiol, 2007;20(6):580-584.

13. McIntosh CA, Macario A, Streatfeild K - How much work is enough? Results of a survey of US and Australian anesthesiologists'perception of parttime practice and part-time training Anesthesiology Clin, 2008;26:693-705.

14. The WHOQOL Group - Development of the World Health Organization WHOQOL-bref. Quality of Life Assessment 1998. Psychol Med, 1998;28:551-558

15. Fleck MPA, Moreno AB, Faerstein E et al. - Propriedades psicométricas do instrumento Abreviado de Avaliação de Qualidade de Vida da Organização Mundial de Saúde no Estudo Pró-Saúde. Cad. Saúde Pública, 2006;22(12):2585-2597.

16. Fleck MPA, Louzada S, Xavier M et al. - Aplicação da versão em português do instrumento abreviado de avaliação da qualidade de vida 'WHOQOLbref'. Rev Saúde Pública, 2000;34(2):178-83.

17. Huang IC, Wu A, Frangakis C - Do the SF-36 and WHOQOL-BREF measure the same constructs? Evidence from Ta population. Quality of Life Research, 2006;15:15-24.

18. Kinzl JF, Traweger C, Trefalt E et al. - Work stress and gender-dependent coping strategies in anesthesiologists at a university hospital J Clin Anesth, 2007; 19:334-338

19. Morais A, Maia P, Azevedo A et al. - Stress and burnout among Portuguese anaesthesiologists. Eur J Anaesthesiol, 2006;23(5):433-439. 